\title{
Utilization of argemone oil biodiesel in commercial IDI- CI engine
}

\author{
ASHISH SAGAR, NIRPAKASH UPPAL AND BALJINDER SINGH
}

\begin{abstract}
In this study the performance and emission characteristics of diesel engine fueled with diesel/Argemone biodiesel blends has been evaluated. An experiment was conducted on an indirect injection (IDI) compression ignition (CI) engine using diesel and diesel/Argemone biodiesel blends. The result shows that with an increase in Argemone biodiesel blend ratio (up to B30) the performance characteristics such as brake thermal efficiency, brake specific fuel consumption, indicated thermal efficiency, indicated mean effective pressure improved and resulted in significant reductions in $\mathrm{CO}$ and $\mathrm{HC}$ emissions. However, an increase in $\mathrm{CO}_{2}$ and $\mathrm{NO}_{x}$ emissions was observed for all biodiesel blends. The maximum value of brake thermal efficiency of 33.57 per cent was obtained for B30 at full load @ $2500 \mathrm{rpm}$. The blends showed deterioration in brake thermal efficiency and brake specific fuel consumption at partial loads and high rpm conditions. The comprehensive analysis of experimental results shows substantial improvement in engine emissions and performance characteristics by the utilization of 30 per cent AOME and without carrying out any engine modification.
\end{abstract}

KEY WORDS : Argemone biodiesel, Performance, Emission, Indirect injection, Low load, Full load

How to cite this Article : Sagar, Ashish, Uppal, Nirpakash and Singh, Baljinder (2016). Utilization of argemone oil biodiesel in commercial IDI-CI engine. Engg. \& Tech. in India, 7 (1) : 33-44. 